\title{
Implikasi Pembelajaran Daring (Online Learning) pada Pembelajaran PAI
}

\author{
${ }^{* 1}$ Mahmudah , ${ }^{2}$ Luthfi Yasykur \\ ${ }^{12}$ Magister Pendidikan Agama Islam, Universitas Maulana Malik Ibrahim Malang \\ *Email:mahmudahmadiun@gmail.com
}

Tanggal Submitt:09/10/2021 Tanggal diterima:08/12/2021 Tanggal Terbit:30/01/2022

\begin{abstract}
The rise of technology has consequences in a variety of areas, including education. The accessibility of the internet has increased access to and the ability to obtain information from anywhere and at any time. Islamic education is in a fortunate position to respond to technological developments and to grab these chances to further innovate in learning in order to create an environment that is receptive, interactive, and acceptable to the challenges and expectations of the internet generation. The research utilizes a library research within descriptiveanalytical type. Utilizing primary and secondary resources on the topics, the data would be displayed and critically analyzed. The findings indicate that online learning in PAI allows students and teachers to accomplish the learning process from anywhere and at any time. Online learning in PAI encourages moral knowing and feeling of PAI materials, although the traditional technique is more appropriate in the dimensions of behavior. As a result, in PAI, the concepts of online learning should be blended with traditional learning so that student understanding is not limited exclusively to what they know and feel, but also to what they do. In conclusion, students should be able to understand all parts of PAI, especially moral knowing, feeling, and behavior.
\end{abstract}

Keywords: Islamic Education, Moral, Online Learning

\begin{abstract}
Abstrak: Perkembangan teknologi memberikan dampak dalam berbagai aspek, termasuk pendidikan. Kehadiran internet meningkatkan akses dan kesempatan untuk mengikuti pembelajaran di mana saja dan di mana saja. Pendidikan Islam menempati posisi strategis untuk merespon perkembangan teknologi dan memanfaatkan peluang ini untuk berinovasi dalam menciptakan ruang belajar yang kondusif, interaktif, dan dapat menjawab tantangan dan tuntutan generasi internet. Studi ini menggunakan penelitian kepustakaan dengan metode deskriptif-analitis. Data akan ditampilkan dan dianalisis secara kritis melalui sumber daya primer dan sekunder dari topik. Hasil penelitian menunjukkan bahwa pembelajaran daring (online learning) PAI memberikan kemudahan bagi siswa dan guru untuk melakukan proses pembelajaran dari mana saja dan kapan saja. Pembelajaran daring PAI juga menumbuhkan pengetahuan (moral knowing) dan perasaan (moral feeling) tentang moralyang termuat dalam materi PAI, tetapi dalam menanamkan perilaku metode konvensional dinilai lebih tepat. Oleh karena itu, konsep pembelajaran daring PAI harus dikombinasikan dengan pembelajaran konvensional sehingga penguasaan siswa tidak hanya terbatas dalam mengetahui dan merasakan tetapi juga menerapkannya dalam kebiasaan. Dengan demikian, diharapkan siswa dapat menguasai semua aspek PAI termasuk moral knowing, moral feeling, dan moral behavior.

Kata Kunci : Moral, Pembelajaran Daring, Pendidikan Agama Islam.
\end{abstract}

\section{Pendahuluan}

Pesatnya perkembangan teknologi membawa dampak besar bagi dunia pendidikan. Berkat kehadiran jaringan internet yang membawa manusia selalu terhubung secara maya, membuat pendidikan kini dapat secara fleksibel dilaksanakan. Fleksibilitas 
waktu dan tempat membawa terobosan baru yang mendobrak tantangan pendidikan era klasik yang harus berada dalam satu ruang dan waktu. Sehingga, dengan fleksibilitas yang ada semakin membuka lebar peluang untuk memperoleh akses pendidikan. Kondisi demikian membawa pendidikan ke era baru yang semakin mudah diakses dan dijangkau oleh siapapun, kapanpun, dan dimanapun.

Membincang masalah teknologi dan pendidikan, saat ini konsep merdeka belajar telah menjadi program nasional, dimana lembaga pendidikan dan guru lebih otonom dalam mengatur dan menyelenggarakan pembelajaran'. Konsep merdeka belajar sejatinya tidak jauh berbeda dari konsep pembelajaran jarak jauh. Keduanya memberikan fleksibilitas ruang dan waktu dalam belajar tanpa mengurangi muatan pembelajaran yang sesungguhnya. Berdasarkan hal tersebut, maka kesempatan untuk mengenyam pendidikan akan terbuka sangat lebar bagi siapapun dan juga peluang interaksi dan kolaborasi dalam pembelajaran akan semakin luas dengan bantuan teknologi.

Adapun pembelajaran jarak jauh membutuhkan beberapa alat pendukung, salah satu diantaranya adalah internet. Kehadiran pembelajaran jarak jauh dengan berbantukan jaringan internet melahirkan online learning atau dikenal dengan pembelajaran daring (dalam jaringan). Pada era Industri Revolusi 4.0 saat ini, konektivitas melalui internet merupakan kebutuhan utama dalam berbagai ranah dan dimensi. Dalam pendidikan saat ini, pembelajaran daring (online learning) adalah kebutuhan yang bersifat vital guna mendukung terselenggara dan kelancaran proses pembelajaran. Selain itu, merebaknya konsep merdeka belajar dengan sasaran generasi $\mathrm{Z}$ yang telah menjadi internet generation sejak dini, maka pembelajaran daring online learning menjadi suatu keharusan ${ }^{2}$.

Dengan demikian, pembelajaran PAI harus bisa merespon kemajuan teknologi dan memanfaatkan kesempatan tersebut untuk semakin berinovasi dalam pembelajaran ${ }^{3}$. Kesan pembelajaran agama yang cenderung klasik dan konvensional harus diubah menjadi interaktif dan dinamis sesuai kebutuhan peserta didik. Maka dengan marujuk pada kebutuhan dan juga berbagai dampak positif, pembelajaran PAI harus berimplikasi dan memanfaatkan pembelajaran daring online learning guna menciptakan suasana pembelajaran yang kondusif, interaktif, dan sesuai dengan tantangan dan tuntutan zaman. Berdasarkan hal tersebut, maka perlu diketahui implikasi pembelajaran daring (online learning) pada pembelajaran PAI.

\section{Metode Penelitian}

Studi ini menerapkan penelitian kepustakaan, yakni serangkaian kegiatan yang berkaitan dengan metode pengumpulan data pustaka, membaca, merekam, dan memproses bahan yang diperoleh ${ }^{4}$. Data dikumpulkan dalam bentuk dokumen. Dokumen-dokumen tersebut terdiri dari buku, jurnal penelitian, dan artikel terkait

$$
51 .
$$

${ }^{1}$ Nadiroh, dkk, Merdeka Belajar dalam Mencapai Indonesia Maju 2045, (Jakarta: UNJ Press, 2020),

${ }^{2}$ Agung Basuki, Sistem Pendidikan bagi Generasi Z (Gen Z), Jurnal Lingkar Widyaiswara, Edisi 7, Nomor 1, Tahun 2020, 43.

${ }^{3}$ Ahmad Jaelani, dkk, Penggunaan Media Online dalam Proses Belajar Mengajar PAI di Masa Pandemi Covid-19: Studi Pustaka dan Observasi Online, Jumal IKA: Ikatan Alumni PGSD UNARS, Volume 8, Nomor 1, Tahun 2020, 14.

${ }^{4}$ Zed, Mestika, Metode Penelitian Kepustakaan, (Jakarta: Yayasan Obor Indonesia, 2008), 1. 
dengan topik pembelajaran daring (online learning), pembelajaran PAI, dan juga moral. Data yang sudah dikumpulkan akan dideskripsikan dan dianalisa dengan menguraikan ide-ide kunci yang ditunjukkan oleh sumber-sumber primer dan sekunder yang dirujuk.

\section{Pembahasan}

\section{A. Sejarah Pembelajaran Jarak Jauh}

Tidak dapat kita pungkiri kembali bahwasanya teknologi informasi dan komunikasi pada dunia Pendidikan akan membuka sebuah cakrawala baru dan akses menuju peningkatan mutu Pendidikan di seluruh jenjang, mulai dasar hingga tingkat perguruan tinggi. Pembelajaran jarak jauh sebetulnya telah ada sejak seratus (100) tahun yang lalu. The University of Queensland adalah salah satu universitas pertama di dunia yang turut menyelenggarakannya. ${ }^{5}$ Di tahun 1880 -an pendidik di University of Cambridge di Inggris mencoba untuk membuat gebrakan gelar melalui korespondensi, yakni pembelajaran yang memanfaatkan media pos sebagai perantara penyelenggaraan pembelajaran dan pada saat itu dibantah (ditolak) oleh pihak universitas. Meski demikian, Universitas Terbuka di Inggris ialah salah satu dari beberapa kampus yang mempelopori pembelajaran jarak jauh di dunia hanya pada tingkat perguruan tinggi saja, dari kegagalan dan ditolaknya metode tersebut, sekarang kampus tersebut menduduki gelar kampus terbaik yang menyelenggarakan metode pembelajaran jarak jauh di dunia, salah satunya adalah Cambridge University dan Imperial College London. ${ }^{6}$

Menurut Mc Isaac dan Gunawardena, pemikiran mengenai pembelajaran jarak jauh telah dikembangkan di University of Chicago di abad ke-19, dengan Willian Rainey Harper sebagai pelopornya (wafat 10 Januari 1906). ${ }^{7}$ Amerika Serikat akan menolong William Rainey Harper untuk memanaje University of Chicago. Harper, seorang profesor yang berbicara menggunakan bahasa Ibrani, beliau menginisiasi ide mengajar melalui surat menyurat ketika bekerja sebagai staf pendidik/guru di Institut Chautanqua, namun pada saat itu ditolak oleh pihak otoritas ${ }^{8}$. Pada tahun 1892, Harper pindah ke University of Chicago sebagai presiden, dan kemudian membuat bagian struktur ekstensi untuk memberikan kegiatan akademik universitas dengan korespondensi (surat). Dan ini adalah program distance learning universitas pertama di dunia.' Adapun sumber lain menyebutkan bahwa pembelajaran jarak jauh (distance learning) mulai muncul di Amerika Serikat pada tahun 1892, The Pennsylvania State University, The University of Chicago, The University of Wisconsin adalah universitas yang

\footnotetext{
hlm 53.

${ }^{6}$ Munir, Pembelajaran Jarak Jaub; Berbasis Teknologi Informasi dan Komunikasi, (Bandung: Alfabeta, 2009), hlm. 12.

${ }^{7}$ Tim Pengembang Ilmu Pendidikan FIP UPI, Ilmu dan Aplikasi Pendidikan, Bagian 4: Pendidikan Lintas Bidang, (Bandung: Imtima, 2007), hlm 489.

${ }^{8}$ Michael Grahame Moore, A Century of Distance Education in United State, (Ohio: Center on Education and Training for Employment, College of Education, the Ohio State University, 2003), 11.

9 Hendra Payobadar, http://payobadar.blogspot.com/2015/04/konsep-sejarah-pendidikanjarak-jauh.html, diakses pada tanggal 27 Februari 2020 pukul 03.22 WIB.
}

${ }^{5}$ Rebecca Grene, Belajar Tak Hanya di Sekolah, terj. Valentinus Eric, (Jakarta: Erlangga, 2006), 
meluncurkan program korespondensi untuk pertama kalinya. ${ }^{10}$ Maka, dapat dikatakan bahwa pembelajaran jarah jauh telah ada sejak abad ke-19, namun dilaksanakan melalui korespodensi secara tertulis.

Pembelajaran jarak jauh disebut juga pendidikan jarak jauh atau dalam bahasa Inggris disebut dengan distance learning/ distance education. Pada tahun 1998, The United States Distance Learning Association memberikan definisi mengenai distance learning sebagai the acquisition of knowledge and skills through mediated information and instruction, encompassing all technologies and other forms of learning at a distance ${ }^{11}$ (perolehan transformasi pengetahuan dan keterampilan melalui informasi dan instruksi yang dimediasi, mencakup semua teknologi dan bentuk pembelajaran lainnya dari jarak yang jauh). Adapun definisi ini tidak terbatas pada pendidikan formal atau informal, namun penekanannya pada jarak yang dimaknai bahwasanya ketika dalam pembelajaran berlangsung peserta didik tidak akan bertatap langsung dengan gurunya, dalam kata lain mereka tidak dalam tempat dan ruangan yang sama.

Dalam Peraturan mentri Nomor 109 Tahun 2013, Distance Learning yang lebih popular disingkat dengan PJJ, ialah proses pembelajaran yang dilaksanakan secara terpisah dari guru dan murid melalui pemakaian berbagai media komunikasi. ${ }^{12}$ Dan adapun sumber belajar ialah bahan ajar dan berbagai informasi yang terus dikembangkan atau dengan sengaja didesain dalam bentuk beragam dengan memanfaatkan teknologi infrmasi dan komunikasi dan juga akan digunakan dalam belajar megajar berlangsung. Sehingga, pendidikan jarak jauh dipahami sebagai pembelajaran jarak jauh yang terselenggara dengan penggunaan bahan ajar yang menggunakan tenologi informasi dan komunikasi.

Pada Permendikbud Nomor 109 Tahun 2013, penekanan penyelenggaraan PJJ hanya pada pendidikan tinggi, sedangkan pada Permendikbud Nomor 119 Tahun 2014 ada beberapa satuan pendidikan. Adapun satuan pendidikan yang dimaksud dalam Permendikbud Nomor 119 Tahun 2014 ialah Pendidikan yang menyelenggarakan layanan formal, informal dan non formal pada setiap tingkat dan jenis pendidikan. ${ }^{13}$ Sehingga, Permendikbud 119 tahun 2014 memberikan wewenang yang lebih luas kepada institusi pendidikan di berbagai jenjang untuk menyelenggarakan Pendidikan Jarak Jauh.

Adapun komponen pembelajaran jarak jauh adalah: ${ }^{14}$

1. Adanya lembaga penyelenggara, baik lembaga konvensional ataupun lembaga khusus penyelenggara pendidikan khusus pembelajaran jarak jauh, baik berupa institusi, universitas, akademi, lembaga diklat, dsb.

\section{hlm 40 .}

${ }^{10}$ Gary E. Miller, Encyclopedia of Distance Learning Second Edition, (United State: IGI Global, 2005),

${ }^{11}$ https://usdla.org/ diakses pada 28 Februari 2020 pukul 12.40 WIB.

12 Kementerian Pendidikan dan Kebudayaan Republik Indonesia Nomor 109 Tahun 2013 tentang Penyelenggaraan Pendidikan Jarak Jauh Jenjang Pendidikan Dasar Dan Menengah, hlm 2.

13 Kementerian Pendidikan dan Kebudayaan Republik Indonesia Nomor 119 Tahun 2014 tentang Penyelenggaraan Pendidikan Jarak Jauh Jenjang Pendidikan Dasar Dan Menengah, hlm 3.

14 Dewi Salma Prawiradilaga, Mozaik Teknologi Pendidikan: E-Learning, (Jakarta: Kencana, 2016), hlm 32 . 
2. Keterpisahan antara pembelajar dan pengajar, baik secara waktu maupun tempat. Dalam arti peserta didik tidak perlu bertemu denga pendidik, mereka dapat mengakses pembelajaran jarak jauh ini dimanapun dan pada kondisi apapun, sehingga dapat terjadinya proses belajar mgajar berlangsung.

3. Adanya telekomunikasi interaktif, interaksi yang terjadi antara pengajar dan pembelajar melalui sistem telekomunikasi.

4. Sharing data, ialah peserta didik akan menerima bahan ajar berupa video, rekaman suara, dan lain sebagainya untuk tercapanya materi ajar.

\section{B. Konsepsi Pembelajaran Daring (Online Learning)}

Istilah online learning identik dengan beberapa istilah lain yakni e-learning, distributed learning, virtual learning, virtual class, e-training dan lainnya. ${ }^{15}$ Online learning adalah salah satu bentuk distance learning or distance education, yang telah menjadi bagian dari sistem pendidikan di Amerika sekaligus menjadi sektor pembelajaran terbesar dalam beberapa tahun terakhir. ${ }^{16}$ Online Learning merupakan suatu sistem yang menggunakan teknologi sebagai upaya meningkatkan kualitas pembelajaran, sehingga online learning memberikan kemudahan bagi peserta didik untuk mengakses dan mencari bahan ajar secara lebih bervariatif. ${ }^{17}$

Pembelajaran daring (online learning) dipahami sebagai akses ke pengalaman belajar melalui penggunaan perangkat dan piranti teknologi yang saling terhubung. Benson dan Conrad mengidentifikasi pembelajaran online sebagai versi terbaru dari pembelajaran jarak jauh yang berfungsi meningkatkan akses dan peluang pendidikan bagi peserta didik. Adapun menurut pendapat lain, online learning tidak hanya membahas aksesibilitas pembelajaran online tetapi juga konektivitas, fleksibilitas, dan kemampuannya untuk mempromosikan berbagai interaksi. Benson juga membuat pernyataan yang jelas bahwa online learning adalah versi yang lebih baru atau, dan versi pembelajaran jarak jauh yang telah diperbaiki. ${ }^{18}$ Jadi, online learning adalah versi terkini dari pembelajaran jarak jauh. Apabila pembelajaran jarak jauh pada zaman dahulu menggunakan metode korespodensi, maka saat ini penggunaan internet menggantikan metode yang lama tersebut dan menjadikannya lebih mudah diakses.

Adapun e-learning dipahami sebagai pendayagunaan teknologi elektronik untuk pembelajaran. Dalam arti lebih luas, e-learning adalah pembelajaran dengan memanfaatkan berbagai perangkat elektronik, baik berupa televisi, radio, CD, computer, dll. Secara singkat, term " $e$ " dimaknai sebagai bagaimana proses pembelajaran dilakukan, yakni pembelajaran yang menggunakan media elektronik. Sementara "learning" dipahami sebagai proses yang memuat materi dan metode bagaimana membantu seseorang untuk belajar. ${ }^{19}$ Berdasar kedua term tersebut, maka

${ }^{15}$ Dewi Salma Prawiradilaga, Mozaik Teknologi Pendidikan: E-Learning, hlm 33.

16 Tuan Nguyen, 2015, The Effectiveness of Online Learning: Beyond No Significant Difference and Future Horizons, MERLOT Journal of Online Learning and Teaching, Vol. 11, No. 2, June 2015, hlm 309.

${ }_{17}$ Munir, Pembelajaran Jarak Jauh berbasis Teknologi Informasi dan Komunikasi, (Bandung: Alfabeta, 2009), hlm 95.

${ }^{18}$ Joi L. Moore, E-Learning, Online Learning, and Distance Learning Environments: Are They The Same?, Elsevier, Internet and Higher Education Vol.14 Tahun 2011, hlm 129-135.

19 Ruth Calvin Clark, Richard E. Mayer, E-learning and the Science of Instruction, (San Fransisco: Pfeiffer, 2003), hlm 13-14. 
dapat ditemukan tujuan dari e-learning adalah untuk membangun pengetahuan dan pengalaman guna membantu individu dalam mencapai tujuan belajarnya.

Sedangkan modus e-learning terbagi menjadi 2 macam, yakni online dan offline. Modus online melahirkan online learning yang menggunakan perangkat elektronik yang terhubung dan membentuk konektivitas tertentu, sehingga penekanannya adalah pada online-nya perangkat elektronik yang terkoneksi antara satu dengan yang lain. Sedangkan modus offline, e-learning dapat dimanfaatkan secara langsung dalam pembelajaran konvesional di kelas. Dengan demikian, dapat digarisbawahi bahwa online learning adalah bagian dari e-learning yang membekali perangkat elektronik dengan sistem konektivitas sehingga terbentuk jaringan.

Dalam Permendikbud Nomor 109 tahun 2013,e-learning adalah pembelajaran yang mana sangat membutuhkan paket informasi dan teknologi informasi, hal itu sangat penting diakses oleh peserta didik dimanapun dan kapanpun. ${ }^{20}$ Artinya $e$ learning menjadi jembatan yang dapat menghubungkan teknologi informasi dan komunikasi untuk mendesain pembelajaran yang mudah diakses.

Meskipun e-learning atau pembelajaran online dapat menjadi komponen pembelajaran di kelas dan jarak jauh, e-learning tidak identik dengan pendidikan jarak jauh. Pembelajaran jarak jauh dapat terlaksana tanpa pembelajaran online, dan pembelajaran online bukanlah pembelajaran jarak jauh yang sempurna. ${ }^{21} \mathrm{Hal}$ ini semakin menegaskan bahwa sejarah pembelajaran jarak jauh telah ada sejak lama bahkan sebelum komputer dan internet ditemukan. Artinya pembelajaran jarak jauh dapat terlaksana tanpa online atau e-learning, begitu pula e-learning tidak hanya digunakan pada pembelajaran jarak jauh tetapi juga pada pembelajaran konvensional. Sedangkan online learning menjadi pendukung pembelajaran daring e-learning dengan penekanan pada konektivitasnya.

Secara umum, pembelajaran daring terjadi pada 2 kondisi lingkungan, synchronous dan asynchronous environment. Adapun asynchronous environment adalah lingkungan di mana komunikasi antara peserta didik dan fasilitator dilakukan melalui komputer dengan beberapa deskripsi pada waktu yang berbeda. Kondisi tersebut memungkinkan orang yang berkomunikasi pada waktu yang berbeda dari lokasi yang berbeda menggunakan komputer sebagai alat untuk mengelola komunikasi tersebut. Sedangkan synchronous environment adalah bentuk komunikasi yang terjadi dalam waktu nyata di mana mereka yang terlibat dalam proses komunikasi hadir pada waktu yang bersamaan, tetapi tidak harus di tempat yang sama. Adapun video conference adalah contoh dari komunikasi synchronous environment. ${ }^{22}$

\footnotetext{
${ }^{20}$ Kementerian Pendidikan dan Kebudayaan Republik Indonesia Nomor 109 Tahun 2013 tentang Penyelenggaraan Pendidikan Jarak Jauh Jenjang Pendidikan Dasar Dan Menengah, hlm 2.

21 A.W. Tony Bates, Technology, E-Learning, and Distance Education, (New York: Routledge, 2005), hlm

22 Alan Jolliffe, Jonatha Ritter, David Stevens, The Online Learning Handbook, (New York: Routledge, 2012), hlm 9 .
} 15. 
Adapun kedudukan online learning dalam pembelajaran adalah: ${ }^{23}$

1. Fungsi Suplemen; dalam fungsi sebagai suplemen, online learning dipandang sebagai tambahan materi pembelajaran yang dapat dipilih oleh siswa untuk diakses guna lebih memperluas wawasan dan memperdalam pemahaman materi pembelajaran. Begitupun sebaliknya, siswa juga diperbolehkan untuk tidak mengakses materi dari online learning.

2. Fungsi Komplemen; komplemen disini ialah pelengkap, dalam fungsi komplemen (pelengkap), apabila ingin melengkapi materi pembelajaran yang ada di dalam kelas itu hanya diprogramkan untuk online learning. Untuk menjadi pengulangan pembelajaran (remedia), materi penguatan (reinforcement), dan pengayaan (enrichment).

3. Fungsi Substituen; dalam fungsi substituen, online learning berfungsi sebagai salah satu alternatif model pembelajaran yang dapat dipilih pembelajar selama belajar. Para pembelajar dimungkinkan untuk tidak mengikuti kelas secara fisik tetapi menggantinya melalui online learning.

\section{Implikasi Pembelajaran Daring (Online Learning) pada Pembelajaran PAI}

Perkembangan teknologi juga telah memasuki dunia pendidikan sehingga membawa dampak yang cukup signifikan. Begitu pun dalam proses pembelajaran, penggunaan beragam media terutama yang berbasis teknologi informasi semakin massif digunakan. Hal tersebut tidak lain karena sasaran didik, yakni siswa merupakan internet generation yang telah akrab dengan dunia teknologi sejak dini, seperti smartphone. ${ }^{24}$ Oleh karena itu, penggunaan media pembelajaran berbasis teknologi dinilai sangat tepat dalam penyampaian materi dan bahan ajar sesuai sasaran pendidikan. Selain itu, karena dengan bantaun teknologi, pembelajaran dapat diakses dengan lebih mudah kapan saja dan dari mana saja.

Adanya pembelajaran berbasis teknologi dinilai sangat membantu dalam pembelajaran PAI. Hal tersebut karena pembelajaran dengan media berbasis teknologi memungkinkan siswa untuk melihat dan mengamati beragam fakta ataupun konsep yang letak dan lokasinya tidak terjangkau. Begitu pula kehadiran pembelajaran daring (online learning) menjadikan siswa dapat dengan mudah untuk mengakses materi dan bahan ajar meskipun sedang tidak berada di sekolah. Sehingga pembelajaran dapat terus terjadi.

Pembelajaran PAI memuat nilai religius yang menjadi salah satu prinsip dalam rangka penguatan pendidikan karakter pada kurikulum 2013 Revisi. Adapun materi PAI meliputi fakta, konsep, prinsip, prosedur, dan nilai. Dalam penyampaiannya, guru dituntut kreatif agar keseluruhan jenis materi dapat tersampaikan dan dipahami oleh siswa dengan baik. Sehingga tercapai tujuan dari setiap kompetensi yang seharusnya dicapai oleh siswa.

Pada siswa yang masih berada di jenjang sekolah dasar, orang tua menjadi salah satu daya pendukung agar pembelajaran PAI secara daring (online learning) dapat berlangsung secara efektif dan optimal. Sementara pada tingkat pendidikan

${ }_{23}$ Munir, Pembelajaran Jarak Jauh berbasis Teknologi Informasi dan Komunikasi, (Bandung: Alfabeta, 2009), hlm 99-101.

24 Siti Anisah, Mau Jadi Guru Millenial?Yuk Buat Media Pembelajaran Berbasis Android, (Sukabumi: Jejak, 2019), hlm 5 . 
menengah, siswa telah dapat mengikuti dan berpartisipasi dalam pembelajaran jarak jauh secara mendiri. Hal ini akan semakin mempermudah guru dalam menyelenggarakan proses pembelajaran dan memungkinkan adanya diskusi interaktif dalam pembelajaran daring (online learning).

Adapun contoh pembelajaran daring (online learning) dalam pembelajaran PAI sangatlah banyak, seperti contoh penggunaan zoom dalam pembelajaran daring di tingkat sekolah dasar. Guru dapat menjelaskan materi melalui sharing screen yang ditambilkan, kemudian Tanya jawab interaktif, ataupun penugasan siswa dapat dilakukan secara daring. Selain itu, beberapa video juga yang tersedia di youtube ataupun streaming dan recorded video guru yang sesuai dengan materi PAI juga dapat dimanfaatkan untuk pembelajaran daring secara asynchronous. Baik dalam bentuk synchronous ataupun asynchronous, pembelajaran PAI dapat dilakukan secara optimal melalui pembelajaran jarak jauh maupun daring.

Adapun pembelajaran daring juga memiliki peran penting dalam rangka penguatan pendidikan karakter pada pembelajaran PAI. Sebagaimana menurut Thomas Lickona bahwasanya karakter dibedakan menjadi 3 bagian dalam pendidikannya, yakni pengetahuan moral (moral knowing), perasaan moral (moral feeling), dan perilaku moral (moral behavior). ${ }^{25}$ Moral knowing atau pengetahuan adalah bagian terpenting yang perlu disampaikan dalam bentuk pembelajaran. Materi-materi terkait dengan nilai moral menjadi pintu utama agar siswa memiliki dasar pengetahuan tentang nilai kebaikan. Adapun pada pengetahuan moral, terdapat 6 elemen penting yang perlu dikuasai oleh siswa, yakni kesadaran mengenai pentingnya moral, pengetahuan akan nilai-nilai moral, pengambilan perspektif, penalaran, pengambilan keputusan, dan pengetahuan akan dirinya sendiri. Melalui pembelajaran daring, penanaman pengetahuan mengenai moral akan jauh lebih variatif, dimana guru dapat menggunakan berbagai media yang tersedia secara daring untuk memberikan pengetahuan kepada siswa mengenai 6 elemen pengetahuan moral. Penggunaan media interaktif yang kontekstual dengan kehidupan sehari-hari juga semakin memudahkan siswa untuk mengetahui dan menguasai konsep pengetahuan moral. Dengan demikian, diharapkan siswa dapat mengetahui tentang nilai-nilai moral/ kebaikan, khususnya dalam ranah kognitif.

Moral feeling atau perasaan moral adalah hal-hal yang mendorong manusia untuk bertindak. Perasaan moral merupakan aspek emosional yang menjadikan seseorang memiliki karakter. Dengan memiliki perasaan tersebut, seseorang diharapkan dapat memahami dan mencintai nilai-nilai kebaikan/ moral. Perasaan ini akan muncul setelah seseorang mengetahui akan nilai kebaikan dan mendorong sekaligus mengontrol seseorang untuk melakukan kebaikan. Perasaan moral meliputi 6 elemen, yakni kemurnian hati nurani, kepercayaan diri, rasa empati, mencintai kebaikan, kendali diri, serta kerendahan hati. Dalam pembelajaran yang dilaksanakan secara daring, upaya menumbuhkan dan mengasah perasaan moral (afektif) dapat dioptimalkan melalui adanya interaksi secara synchronous. Selain itu, pembelajaran yang didesain secara berkelompok juga dapat menjadi variasi lain agar terjadi interaksi

25 Dalmeri, Pendidikan untuk Pengembangan Karakter: Telaah terhadap Gagasan Thomas Lickona dalam Educating for Character, Al-Ulum, Volume 14, Nomor 1, Juni 2014, hlm 272. 
antar siswa. Dalam interaksi yang terjadi antara guru dan siswa, maupun sesama siswa dapat ditanamkan perasaan moral agar semakin peka dan menimbulkan kecintaan terhadap kebaikan.

Adapun manifestasi dari pengetahuan dan perasaan moral adalah perilaku atau tindakan (moral behavior). Dalam upaya mewujudkan adanya tindakan yang bermoral maka terdapat 3 elemen yang perlu diperhatikan, yakni kompetensi, keinginan, dan kebiasaaan ${ }^{26}$. Oleh karena terkait dengan tindakan langsung, bahkan kebiasaan maka pembelajaran daring (online learning) tidak sepenuhnya dapat mengakomodasi pembelajaran dalam ranah ini (psikomotrik). Meskipun demikian, terdapat beberapa alternatif yang dapat dilakukan, salah satunya adalah peran aktif orang tua guna turut serta membiasakan perilaku moral sebagai role model bagi anak. Namun kadang kala hal tersebut sulit untuk dilaksanakan dan dievaluasi karena beragamnya latar belakang dan juga kondisi orang tua siswa. Maka tak dapat dinafikkan bahwasanya pembelajaran konvensional secara luring memang lebih efektif dalam membiasakan karakter bagi siswa, karena kompetensi yang secara langsung dicontohkan oleh guru sebagai role model, kemudian dorongan keinginan apabila berada dalam lingkungan komunal, serta pembiasaan yang lebih mudah diatur dan diorganisir menjadi keunggulan yang tidak dapat diperoleh secara daring. Maka, alternatif lain yang dapat dilakukan adalah dengan menerapkan perpaduan antara pembelajaran daring (online learning) dan pembelajaran konvensional secara luring, atau yang dikenal dengan istilah blended learning. Sehingga, siswa dapat menunjukkan dan terbiasa untuk melakukan perilaku yang bermoral.

Berdasarkan pemaparan proses penanaman moral dengan penerapan pembelajaran daring (online learning) dalam PAI, diketahui bahwa dalam ranah pemberian wawasan dan pengetahuan pembelajaran daring (online learning) dapat secara efektif dilaksanakan. Tetapi dalam ranah pengamalan dan pembiasaan perilaku, pembelajaran konvensional dinilai lebih tepat karena guru dapat secara langsung memberikan pemahaman, memberikan koreksi juga mengapresiasi atas sesuatu yang telah dilakukan oleh siswa, terutama dalam penanaman karakter atau akhlaq pada diri siswa.

Sehingga dapat disimpulkan bahwa mata pelajaran yang berkaitan dengan karakter dan moral tidak hanya dipahami sebatas konsep tetapi juga menjadi pengamalan dalam kehidupan sehari-hari siswa. Oleh karena itu, konsep blended learning dinilai sangat tepat dan efektif dalam pembelajaran PAI. Dalam prosentase pembelajaran daring, penguatan konsep, wawasan, dan pengetahuan siswa dibentuk secara riil, mudah dipahami, dan mudah diakses. Sementara dalam pembelajaran konvensional, perilaku siswa semakin diasah dan dikuatkan dengan praktik secara langsung juga pemberian stimulus dan respon yang diharapkan dapat menguatkan dan membentuk karakter siswa yang bermoral dan berakhlaq mulia.

${ }^{26}$ Umi Anugerah Izzati, Bachtiar Syaiful Bachri, M. Sahid, Dian Eka Indriani, Character Education: Gender Differences in Moral Knowing, Moral Feeling, and Moral Action in Elementary Schools in Indonesia, Journal for the Education of Gifted Young Scientists, Vol.7, Number 3, 2019, hlm 550. 


\section{Catatan Akhir}

Implikasi pembelajaran daring (online learning) dalam pembelajaran PAI khususnya dalam penanaman karakter yakni memungkinkannya penanaman pengetahuan (moral knowing) dan perasaan (moral feeling), namun dalam pembiasaan perilaku (moral behavior) pembelajaran konvensional dinilai lebih tepat dan efektif. Oleh karena itu, konsep pembelajaran daring (online learning) dalam PAI perlu memadukan dengan pembelajaran konvensional (blended learning) agar penguasaan siswa tidak hanya terbatas pada pengetahuan (moral knowing) dan perasaan (moral feeling), tetapi juga pengamalan (moral behavior) yang lebih utama. Dengan demikian, diharapkan tercetak siswa yang menguasi wawasan ilmu ke-Islam-an juga mengamalkannya dalam bentuk akhlaq yang mulia.

\section{Daftar Rujukan}

Anisah, Siti, 2019, Mau Jadi Guru Millenial?Yuk Buat Media Pembelajaran Berbasis Android, Sukabumi: Jejak.Basuki, Agung, Sistem Pendidikan bagi Generasi Z (Gen Z), Jurnal Lingkar Widyaiswara, Edisi 7, Nomor 1, Tahun 2020.

Bates, A.W. Tony, 2005, Technology, E-Learning, and Distance Education, New York: Routledge.

Clark, Ruth Calvin., E. Mayer, Richard., 2003, E-learning and the Science of Instruction, San Fransisco: Pfeiffer.

Dalmeri, Pendidikan untuk Pengembangan Karakter: Telaah terhadap Gagasan Thomas Lickona dalam Educating for Character, Al-Ulum, Volume 14, Nomor 1, Juni 2014.

Grene, Rebecca, 2006, Belajar Tak Hanya di Sekolah, terj. Valentinus Eric, Jakarta: Erlangga.https://usdla.org/ diakses pada 28 Februari 2020 pukul 12.40 WIB.

Izzati, Umi Anugerah, Bachtiar Syaiful Bachri, M. Sahid, Dian Eka Indriani, Character Education: Gender Differences in Moral Knowing, Moral Feeling, and Moral Action in Elementary Schools in Indonesia, Journal for the Education of Gifted Young Scientists, Vol.7, Number 3, 2019.

Jaelani, Ahmad, dkk, Penggunaan Media Online dalam Proses Belajar Mengajar PAI di Masa Pandemi Covid-19: Studi Pustaka dan Observasi Online, Jurnal IKA: Ikatan Alumni PGSD UNARS, Volume 8, Nomor 1, Tahun 2020.

Jolliffe, Alan., Ritter, Jonathan., Stevens, David., 2012, The Online Learning Handbook, New York: Routledge.

Kementerian Pendidikan dan Kebudayaan Republik Indonesia Nomor 109 Tahun 2013 tentang Penyelenggaraan Pendidikan Jarak Jauh Jenjang Pendidikan Dasar Dan Menengah.

Kementerian Pendidikan dan Kebudayaan Republik Indonesia Nomor 119 Tahun 2014 tentang Penyelenggaraan Pendidikan Jarak Jauh Jenjang Pendidikan Dasar Dan Menengah.

Mestika, Zed, 2008, Metode Penelitian Kepustakaan, Jakarta: Yayasan Obor Indonesia.

Miller, Gary E., 2005, Encyclopedia of Distance Learning Second Edition, United State: IGI Global.

Moore, Joi L., 2011, E-Learning, Online Learning, and Distance Learning Environments: Are They The Same?, Elsevier, Internet and Higher Education Vol. 14 Tahun 2011.

Moore, Michael Grahame, 2003, A Century of Distance Education in United State, Ohio: Center on Education and Training for Employment, College of Education, the Ohio State University. 
Munir, 2009, Pembelajaran Jarak Jaub; Berbasis Teknologi Informasi dan Komunikasi, Bandung: Alfabeta.

Nadiroh, dkk, 2020, Merdeka Belajar dalam Mencapai Indonesia Maju 2045, Jakarta: UNJ Press.

Nguyen, Tuan, 2015, The Effectiveness of Online Learning: Beyond No Significant Difference and Future Horizons, MERLOT Journal of Online Learning and Teaching, Vol. 11, No. 2, June 2015.

Payobadar, Hendra, http://payobadar.blogspot.com/2015/04/konsep-sejarahpendidikan-jarak-jauh.html, diakses pada tanggal 27 Februari 2020 pukul 03.22 WIB.

Prawiradilaga, Dewi Salma, 2016, Mozaik Teknologi Pendidikan: E-Learning, Jakarta: Kencana.

Tim Pengembang Ilmu Pendidikan FIP UPI, 2007, Ilmu dan Aplikasi Pendidikan, Bagian 4: Pendidikan Lintas Bidang, Bandung: Imtima. 